Supporting Information:

\title{
Fused Filament Fabrication 4D Printing of a Highly Extensible, Self-Healing, Shape Memory Elastomer Based on Thermoplastic Polymer Blends
}

Bangan Peng ${ }^{1, s}$, Yunchong Yang ${ }^{1, s}$, Tianxiong Jü ${ }^{2}$ Kevin A. Cavicchi ${ }^{1, *}$

${ }^{1}$ School of Polymer Science and Polymer Engineering, University of Akron, Akron, Ohio 44325, United

States

${ }^{2}$ Department of Macromolecular Science and Engineering, Case Western Reserve University, Cleveland, Ohio, 44106, United States

${ }^{*}$ Corresponding Author: Kevin A. Cavicchi, Email: kac58@uakron.edu. Phone: 330-972-8368.

§These authors contributed equally to this work. 


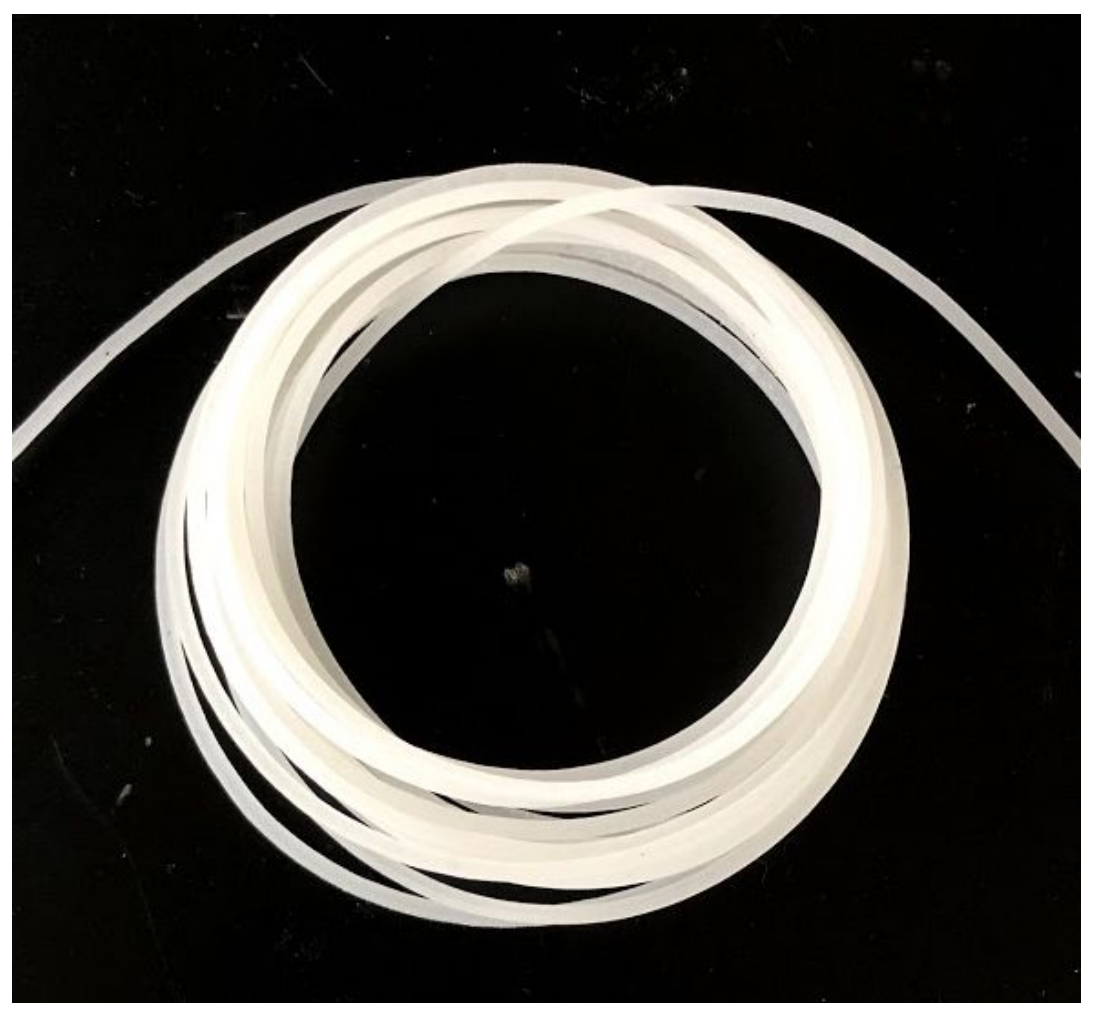

Figure S1. The filament made from PCL/SEBS (G1652). 

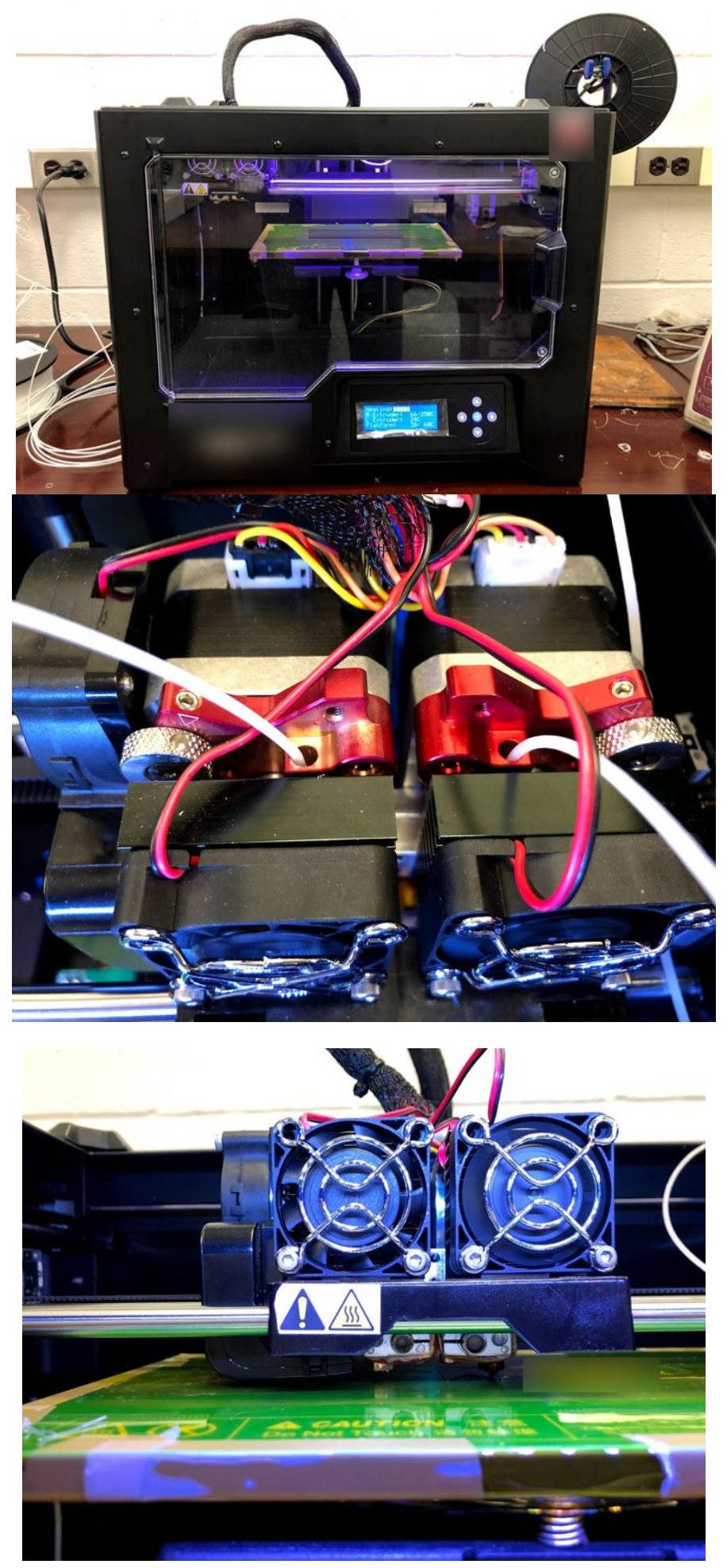

Figure S2. The 3D printer (top) and the top view (middle) and side view (bottom) of the flexion extruder. 


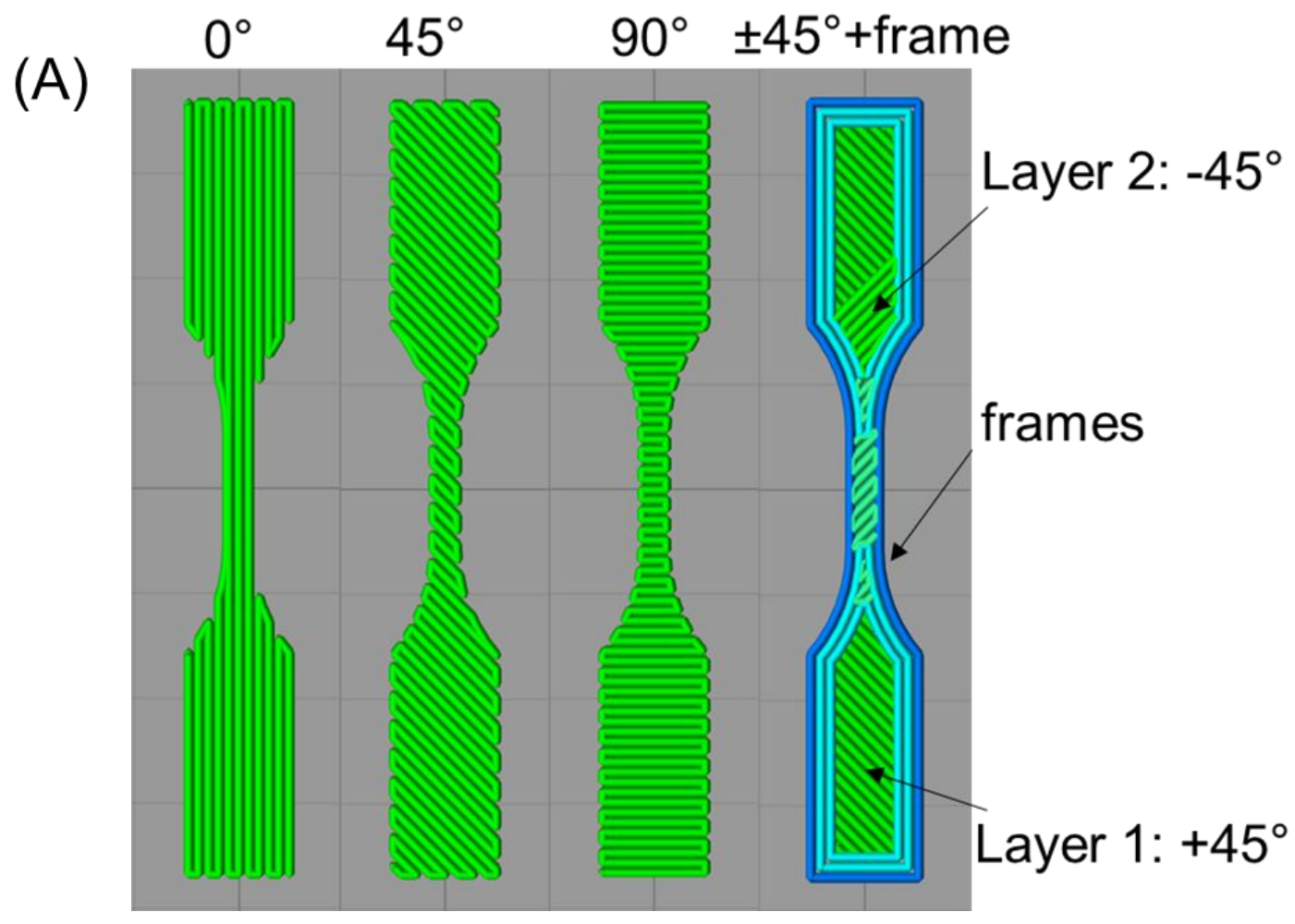

(B)

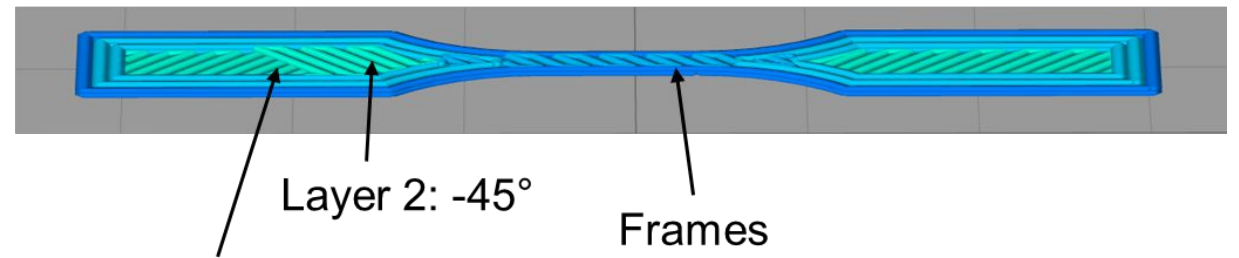

Layer $1:+45^{\circ}$

(C)

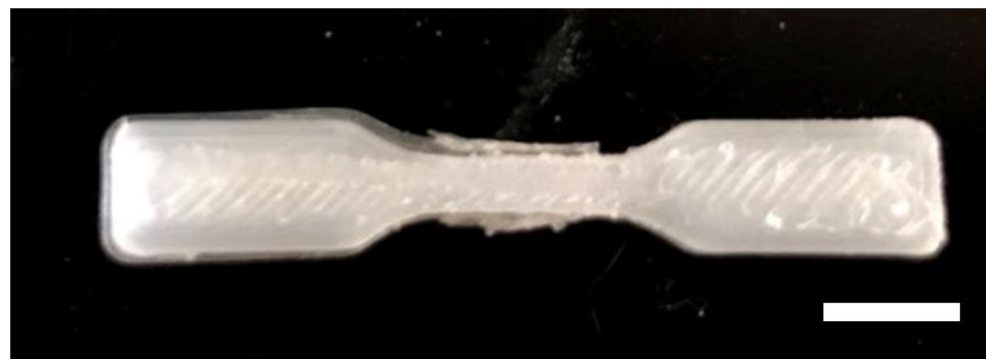

Figure S3. (A) From left to right, printing patterns of $0^{\circ}, 45^{\circ}, 90^{\circ}$ raster angles (one layer of $0^{\circ}$, $45^{\circ}$, and $90^{\circ}$ patterns, respectively) and the software default setting (two layers of $+45^{\circ}$ and $-45^{\circ}$ with three outer frames, $\pm 45^{\circ}$ pattern). (B) Side view of the $\pm 45^{\circ}$ pattern (C) Image of a tensile bar printed with the default $\pm 45^{\circ}$ pattern. Scale bar, $5 \mathrm{~mm}$ 


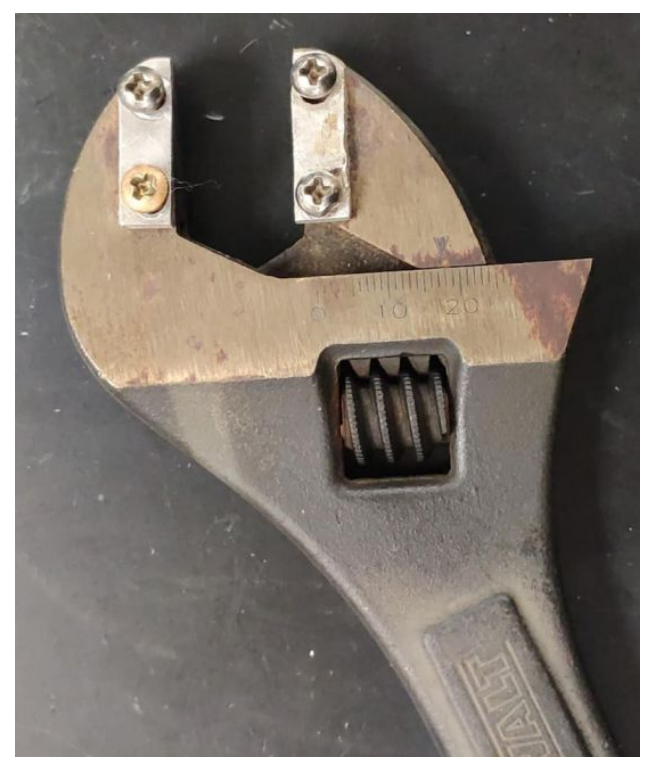

Figure S4. The home-made scale crescent wrench used for manual shape memory test. 


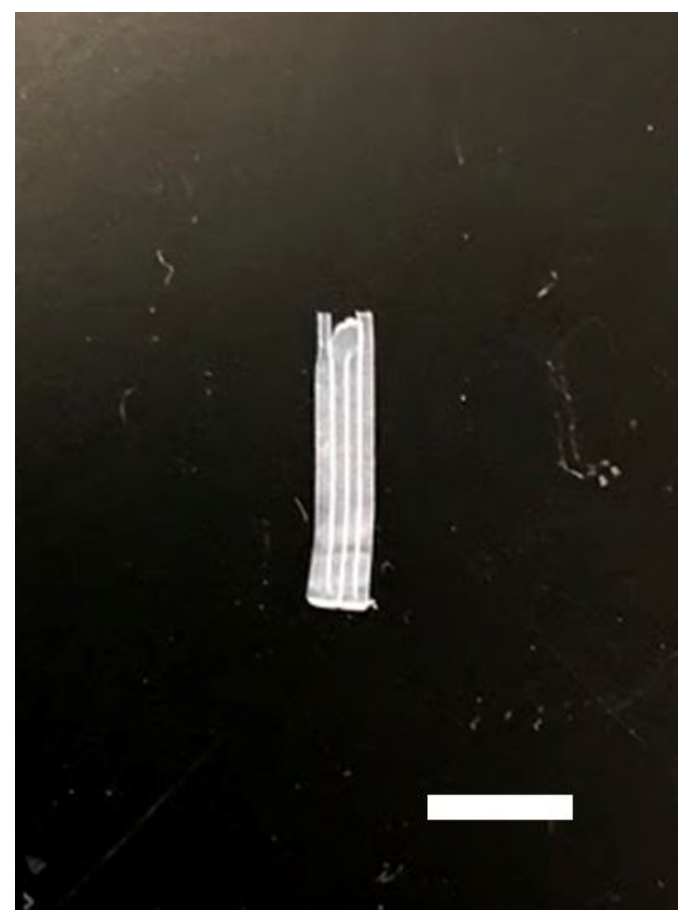

Figure S5. The sample 3D printed at $0^{\circ}$ raster angle for SAXS and WAXS experiments. Scale bar, $5 \mathrm{~mm}$ 


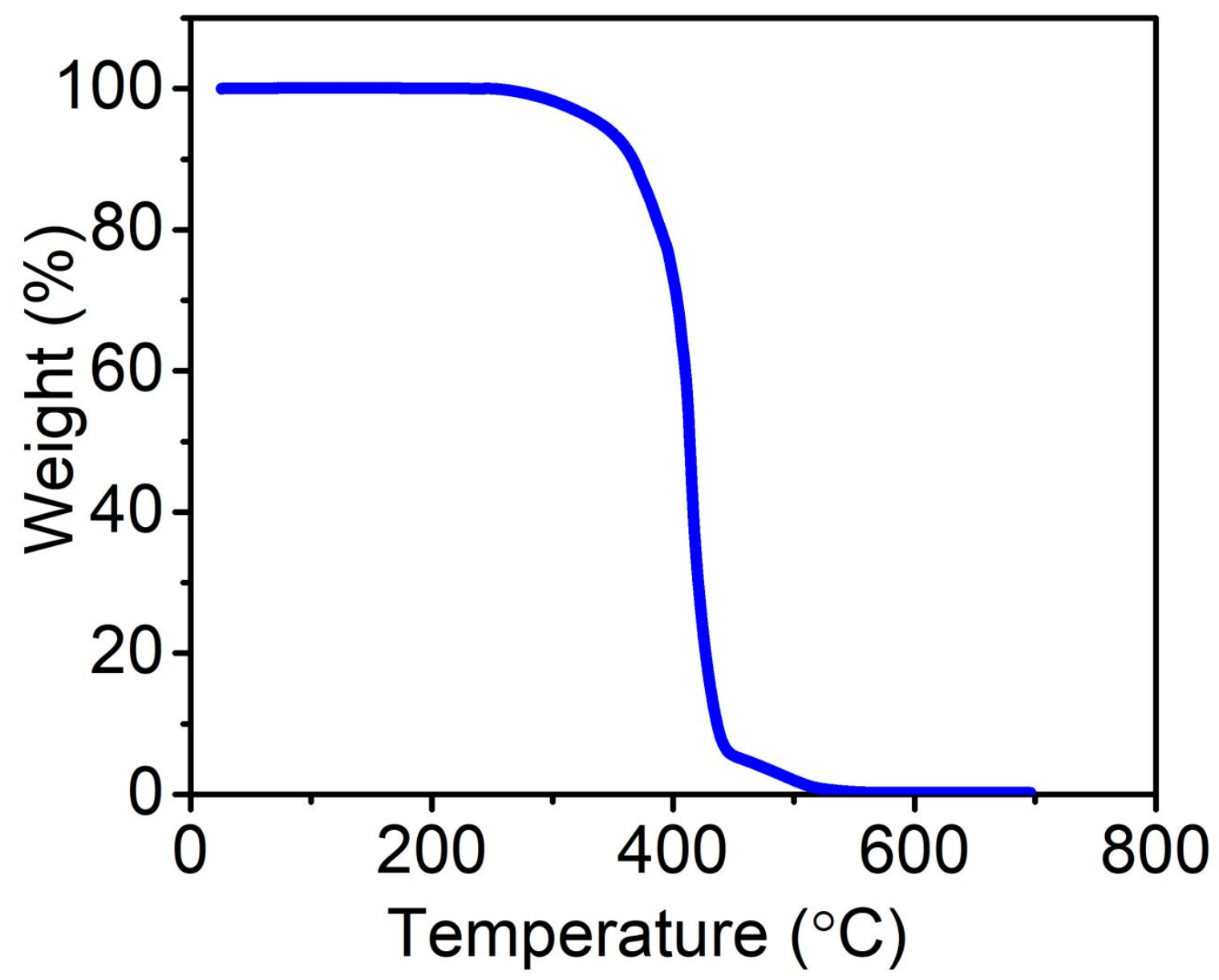

Figure S6. TGA thermogram of $20 \%$ PCL/ $80 \%$ SEBS under air purge. 


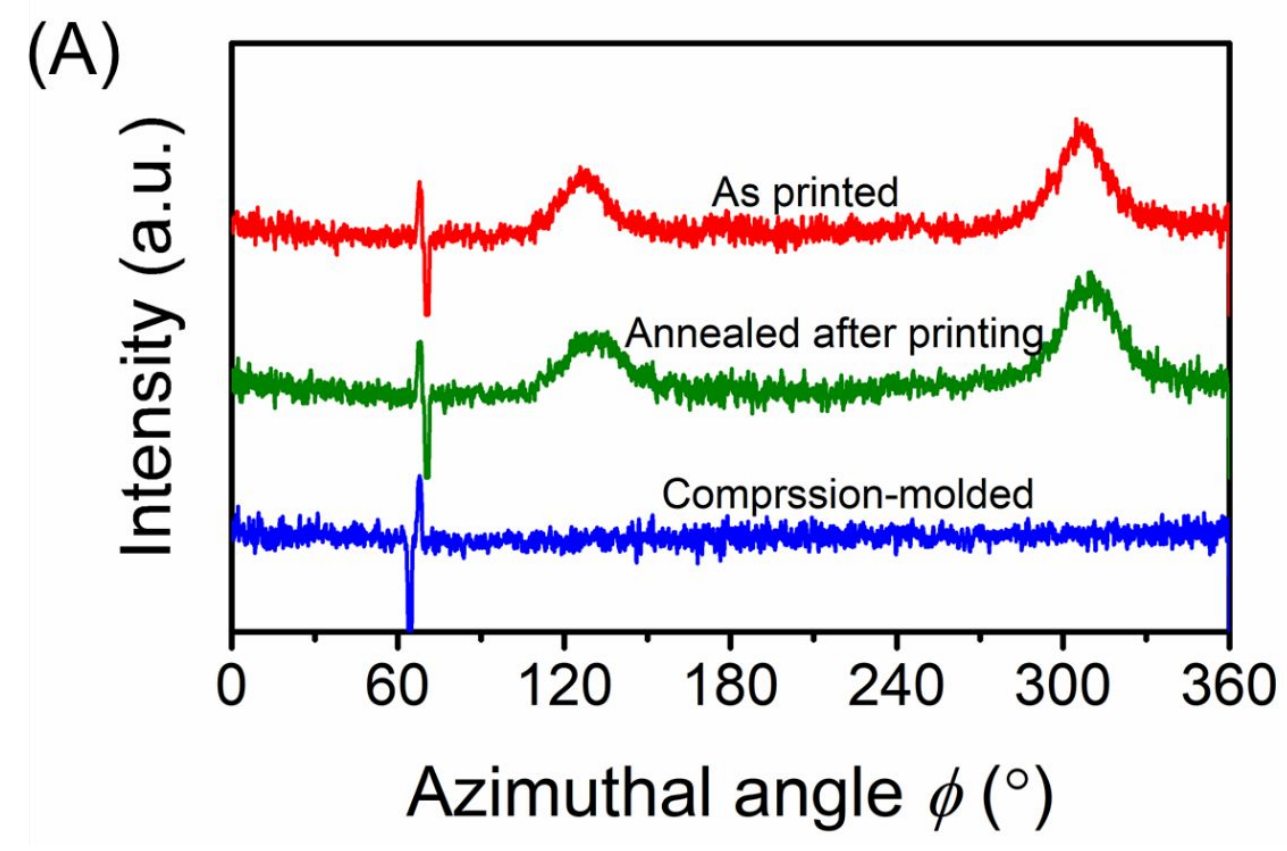

(B) Print direction

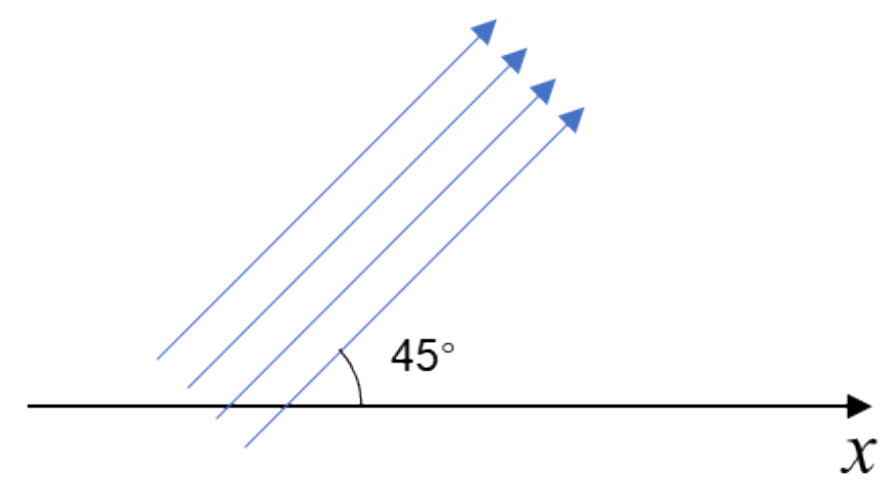

Figure S7. (A) Intensity profile of (200) reflection vs. azimuthal angle of as printed, annealed and compression-molded samples. (B) Schematic illustration of the angle at which the printing direction was aligned. The sample was printed at $0^{\circ}$ raster angle (Figure S5) and titled in the loading stage with ca. $45^{\circ}$ angle with respect to the $\mathrm{x}$-axis of the detector 


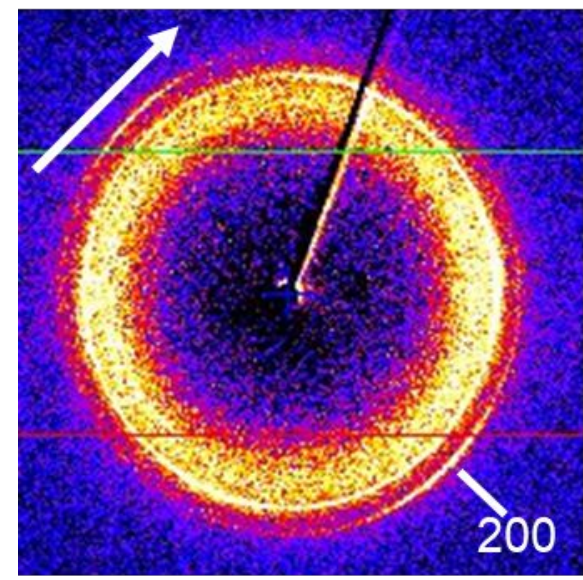

Figure S8. 2D WAXS pattern of 3D printed sample annealed at $80^{\circ} \mathrm{C}$ for 30 minutes. The arrow indicates the printing direction in the $3 \mathrm{D}$ printed samples. 

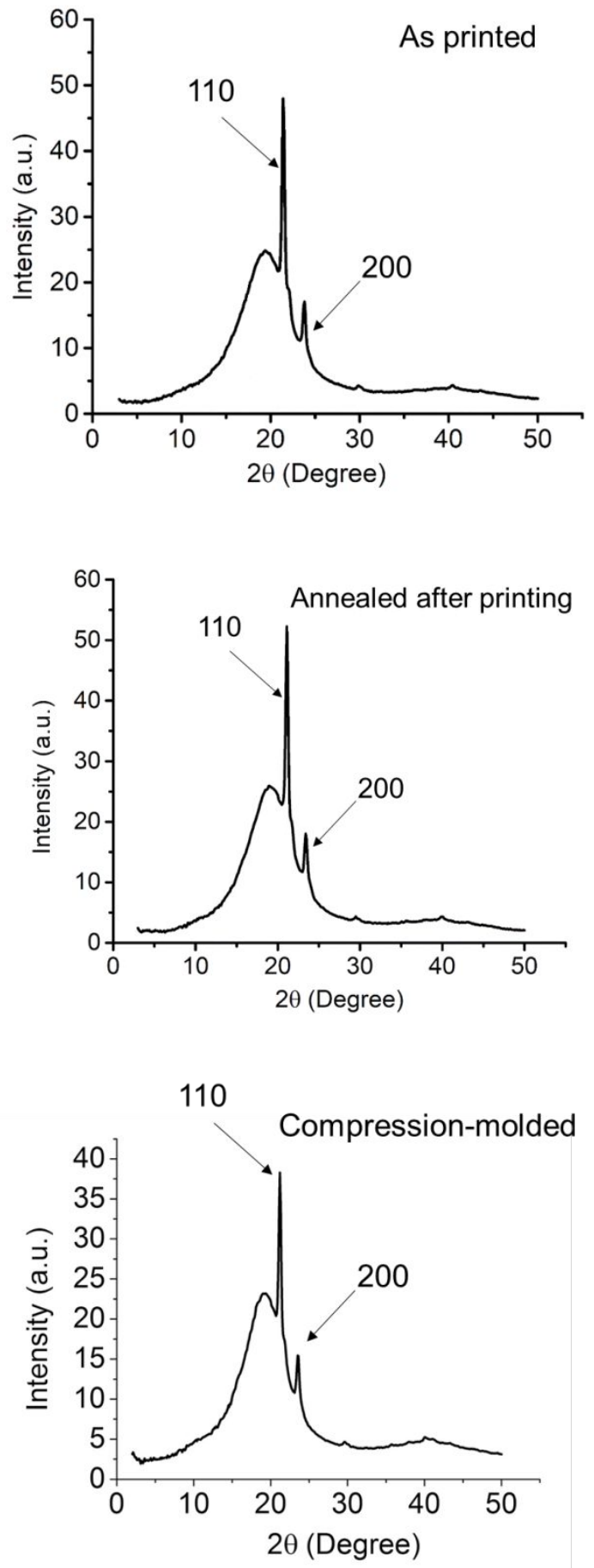

Figure S9. 1D WAXS intensity profile of as printed (top), annealed after printing (middle) and compression-molded sample (down). 


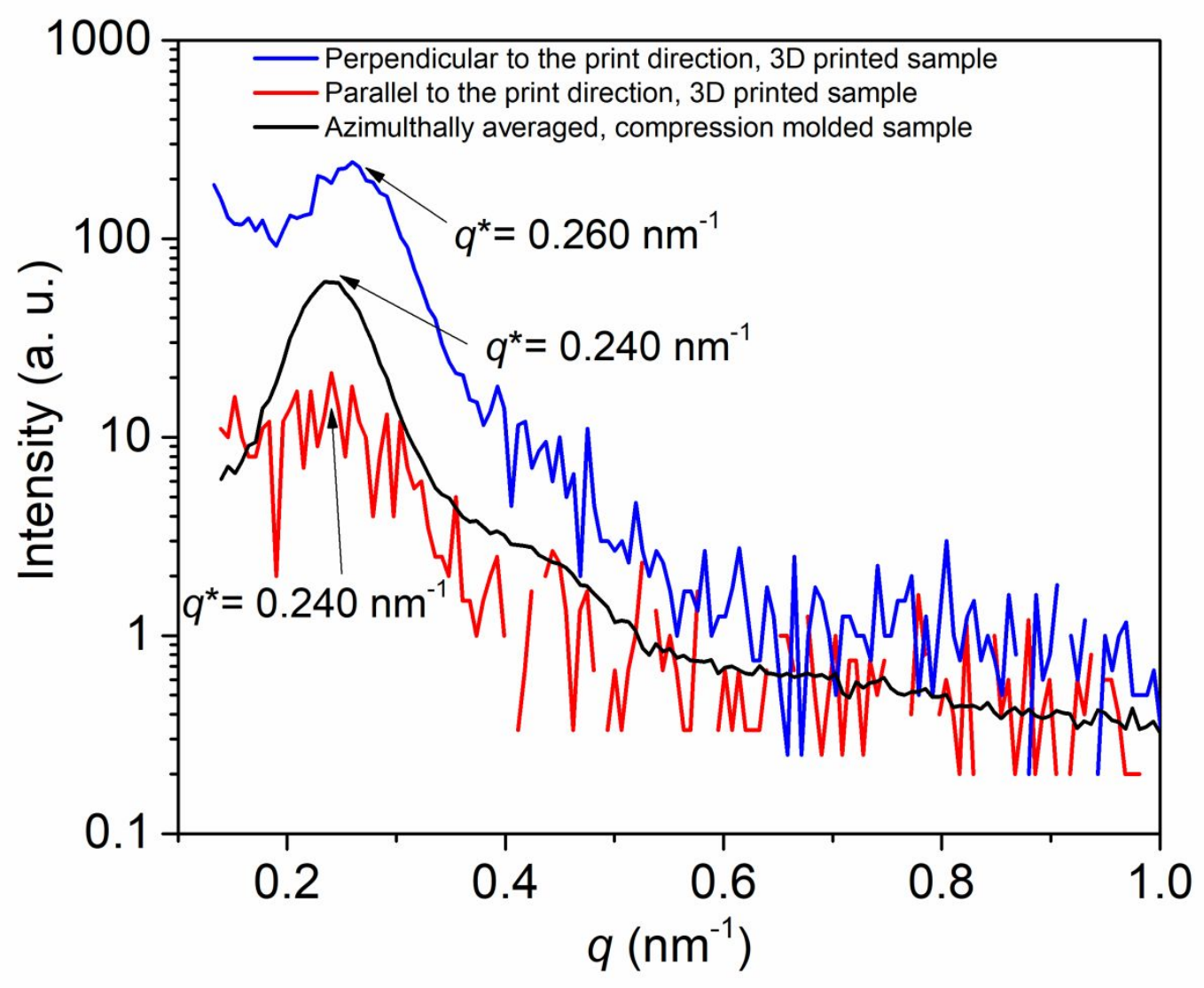

Figure S10. Intensity profile at meridional (parallel to print direction) and equatorial (perpendicular to print direction) directions of the 3D printed sample and azimuthally averaged intensity profile of the compression-molded sample vs. scattering vector $(q)$. 

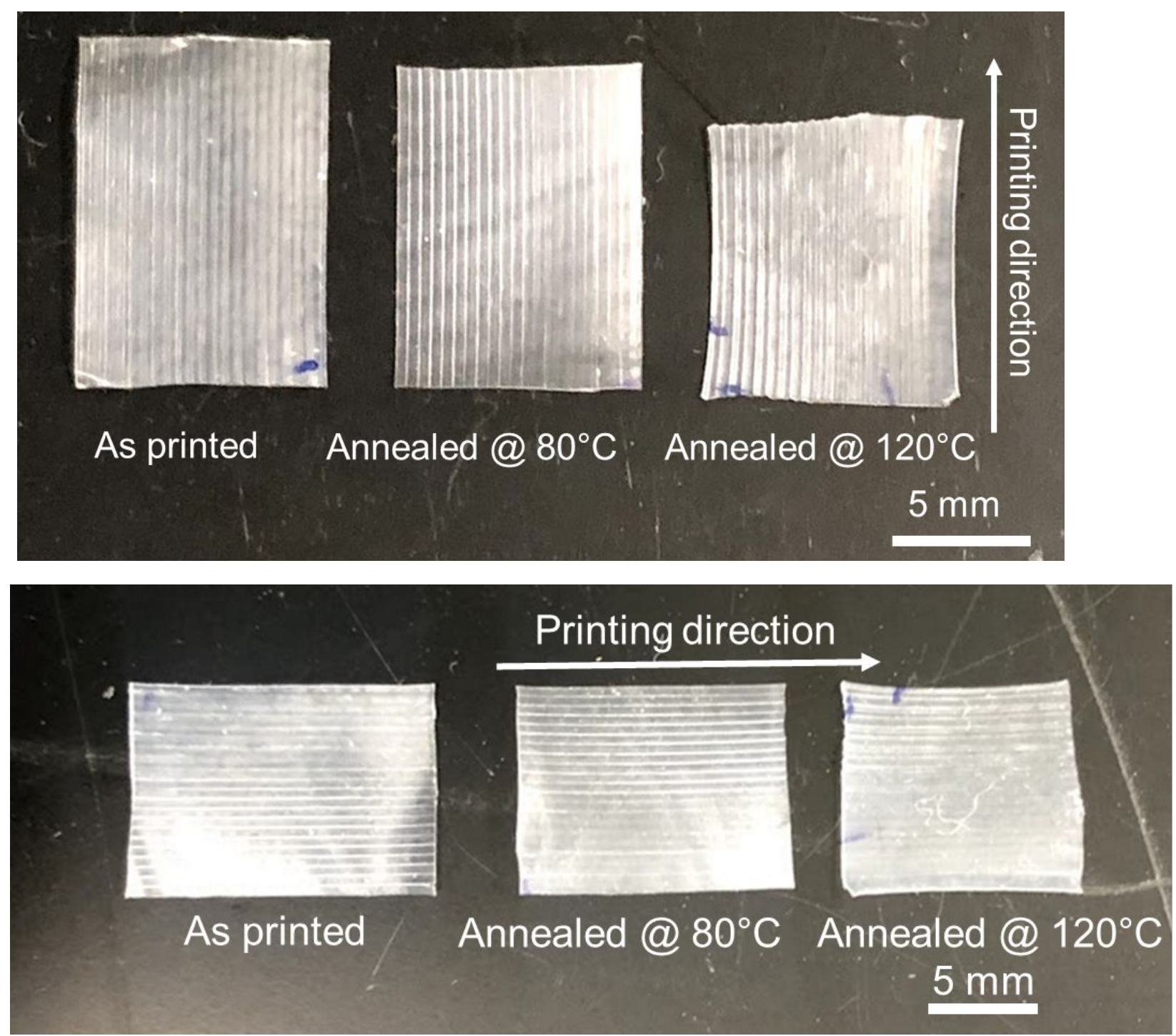

Figure S11. Comparison of the as printed section and the sections annealed at 80 and $120^{\circ} \mathrm{C}$ for 30 minutes. 

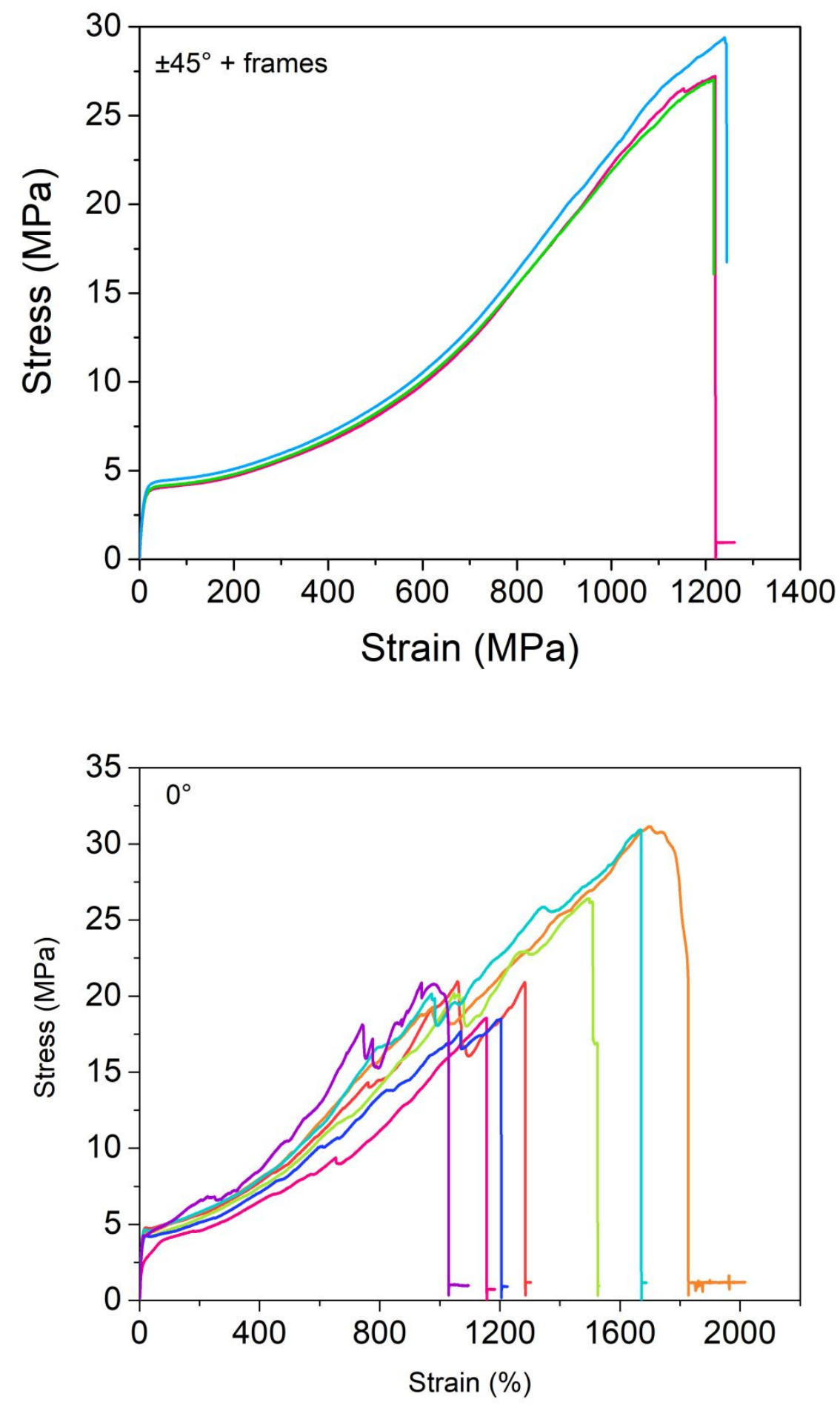

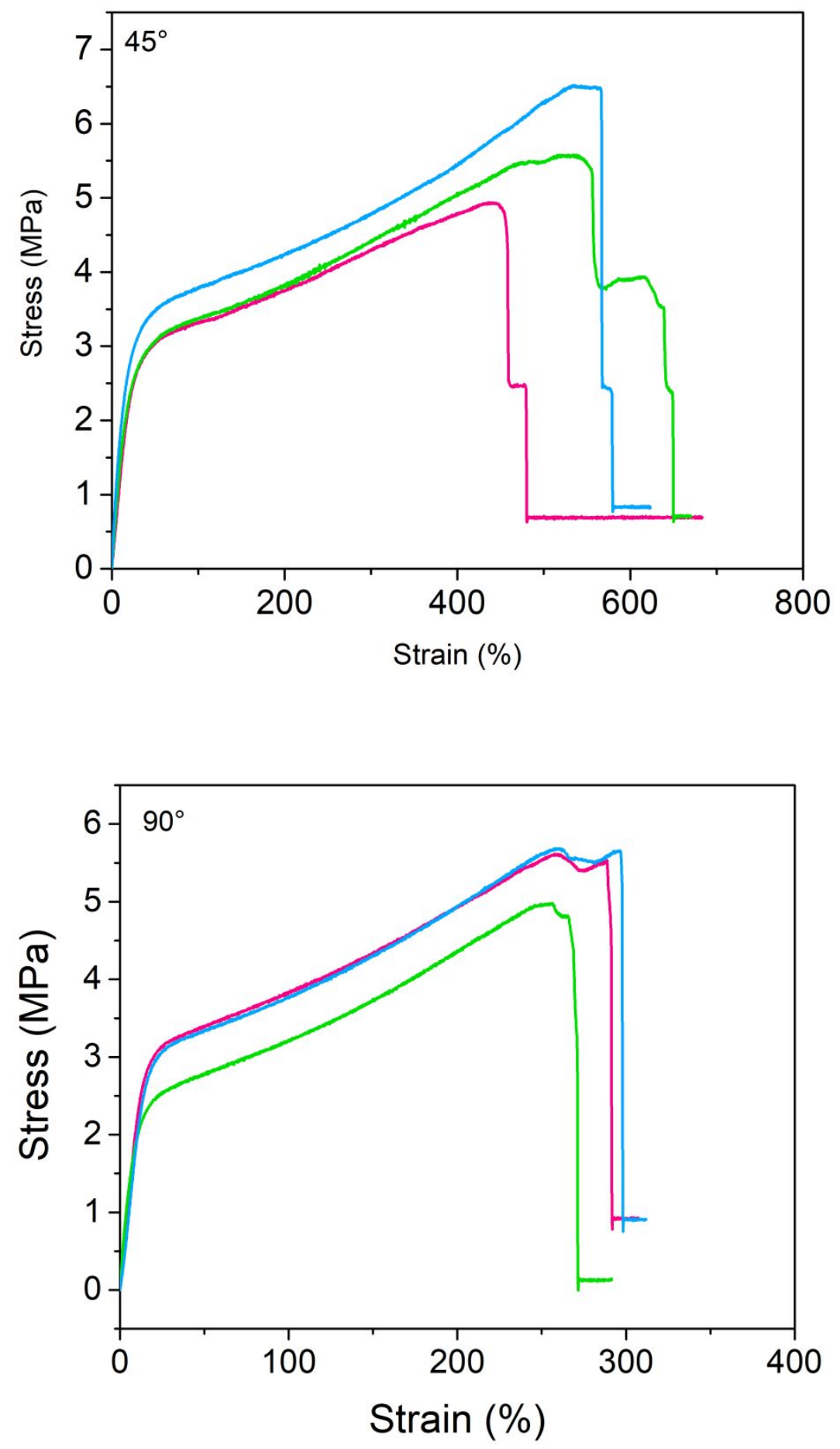

Figure S12. Tensile tests of 3D printed samples with different patterns $\left( \pm 45^{\circ}, 0^{\circ}, 45^{\circ}, 90^{\circ}\right.$ patterns). 

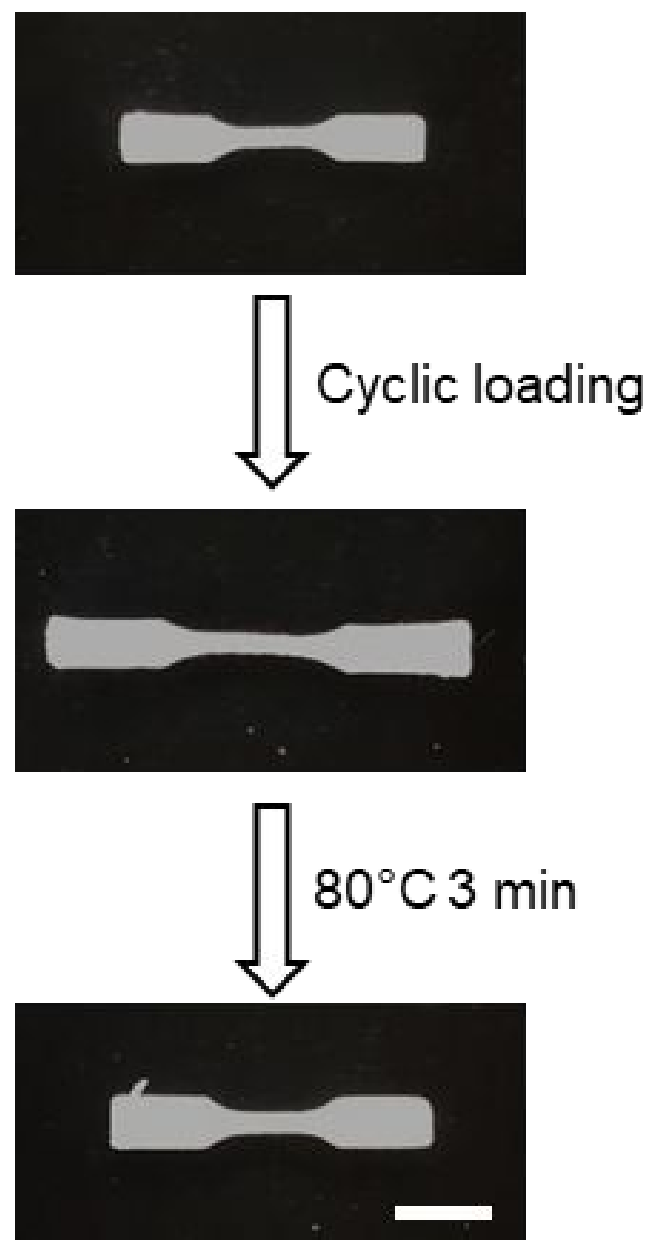

Figure S13. Images of a tensile bar in its initial state (top), after cyclic loading (middle) and after heated at $80^{\circ} \mathrm{C}$ for 5 minutes (down). Scale bar, $1 \mathrm{~cm}$. The plastic deformation accumulated during cyclic loading was eliminated by heating. 
Table S1. Melting enthalpy ( $\Delta H_{\mathrm{m})}$ of different compositions integrated from DSC curves.

\begin{tabular}{|c|c|c|c|}
\hline PCL $(\mathrm{wt} \%)$ & SEBS $(\mathrm{wt} \%)$ & $\Delta H_{\mathrm{m}}(\mathrm{J} / \mathrm{g})$ & Crystallinity $\chi(\%)$ \\
\hline 100 & 0 & 51.39 & 36.8 \\
\hline 80 & 20 & 41.79 & 37.4 \\
\hline 60 & 40 & 30.74 & 36.7 \\
\hline 40 & 60 & 20.34 & 36.5 \\
\hline 20 & 80 & 10.45 & 37.5 \\
\hline
\end{tabular}


Table S2. Shape fixity $\left(R_{\mathrm{f}}\right)$ and recovery $\left(R_{\mathrm{f}}\right)$ ratios of 3D printed sample and compressionmolded sample.

\begin{tabular}{|c|c|c|c|c|}
\hline \multirow{2}{*}{ Cycle No. } & \multicolumn{2}{|c|}{ 3D printed } & \multicolumn{2}{c|}{ Compression-molded } \\
\cline { 2 - 5 } & $R_{\mathrm{f}}(\%)$ & $R_{\mathrm{r}}(\%)$ & $R_{\mathrm{f}}(\%)$ & $R_{\mathrm{r}}(\%)$ \\
\hline 1 & 90.4 & 95.9 & 84.4 & 77.9 \\
\hline 2 & 90.9 & 95.5 & 85.3 & 92.2 \\
\hline 3 & 90.6 & 96.4 & 84.7 & 94.7 \\
\hline
\end{tabular}

